\title{
An Empirical Estimation of Okun'S Law in Context of Pakistan
}

\author{
Misbah Akram ${ }^{1, *}$, Shahzad Hussain ${ }^{2}$, Syed Hasan Raza ${ }^{3}$, Saqib Masood ${ }^{4}$ \\ ${ }^{1}$ National University Of Modern Languages Faisalabad Campus, Pakistan \\ ${ }^{2}$ National Defence University Islamabad, Pakistan \\ ${ }^{3}$ National University Of Modern Languages Faisalabad Campus, Pakistan \\ ${ }^{4}$ Sodertorn University Sweden \\ *Corresponding author: misbahakram55@yahoo.com
}

Received July 04, 2014; Revised August 13, 2014; Accepted August 21, 2014

\begin{abstract}
This research work is on the topic of an empirical estimation of Okun's law in context of Pakistan. Coefficient of Okun's law is estimated to check whether this law exist in Pakistan's economy or not. Okun's law shows three to one link between real GDP and rate of unemployment. Time series data of real GDP and rate of unemployment of Pakistan have been used to find the validity of Okun's law. Duration of data is 1972 - 2012. Different three versions of Okun's law gap version, difference version and dynamic version are used to calculate the Okun's coefficient. Ordinary least square method is applied for analysis. The empirical results show that there is no existence of Okun's law in Pakistan's economy. Coefficients estimated by using all the three versions are very small and reject the presence of this law in Pakistan.
\end{abstract}

Keywords: Okun's law, gap version, difference version, dynamic version, GDP, unemployment, potential output, natural rate of unemployment, OLS

Cite This Article: Misbah Akram, Shahzad Hussain, Syed Hasan Raza, and Saqib Masood, "An Empirical Estimation of Okun'S Law in Context of Pakistan.” Journal of Finance and Economics, vol. 2, no. 5 (2014): 173177. doi: 10.12691/jfe-2-5-7.

\section{Introduction}

Arther Okun in 1962 presented a law about the relationship between real GDP and unemployment rate. He suggested a three percent growth in output is related with a one percent decrease in the rate of unemployment, ceteris paribus. When there will increase in production, more workers will be required to produce extra units. And there will be reduction in unemployment, so with the increase in the GDP, unemployment will decrease. But both the variables do not change with same proportion. GDP changes more rapidly rather than to change in unemployment. At the earlier studies Okun estimated the three present increase in GDP cause one present decrees in unemployment. But the later studies which were based on the latest data showed that two present GDP growths are associated with one present decrease in unemployment. The value of the coefficient may vary from country to country and economy to economy depending on the circumstances and economic situations. (Lal at el. 2010)

Estimation of Okun's coefficient which is a measure of the responsiveness of unemployment to output growth is important because it shows the cost of unemployment in terms of output. Okun's law is often used as a scale for computing the cost of unemployment. However, it is also essential to examine and watch out if the impact of the variations in the country's growth to the variations of unemployment is harmful to the citizen of Pakistan and in which the appropriate policies are needed. This paper aimed at the estimation of the coefficient of Okun's law to check the existence of Okun's law from Pakistan economy and to give some policy recommendations in the light of estimated coefficient. The purpose of this paper is to calculate Okun's coefficient, and discover the validity of Okun's law for Pakistan. The inspiration for doing this work is straight forward, if Okun's law is valid for Pakistan this will give an idea about the kind of unemployment which would then suggest whether or not unemployment can be decreased by increasing growth.

This research paper estimates the validity of Okun's law in Pakistan's economy whether both unemployment rate and GDP growth are linked with each other or not to find the intensity of this relationship as well as direction of association. According to Okun's formulation, GDP growth causes diminishing trend in unemployment rate. The growth in GDP means an increase in real GDP over time and real GDP means value of all goods and services formed in any economy adjusted for price changes. This research is important not only in order to know how much the output of this country causes changes in unemployment rate but also the mechanism through which these effects take place. For a country that has suffered considerably from the persistence of high regional unemployment dispersion, the knowledge of this relationship for is important from the point of view of the implementation of appropriate economic policies. 
This paper includes the three versions of Okun's law. Dynamic version is also used for the estimation of coefficient. This version has not been used by any researcher before in context of Pakistan's economy. Extended time period from 1972 to 2012 is used. The implementation of adequate policies to continue with the reduction of unemployment and then with a higher growth of output is one of the main goals of Pakistani national and regional policy makers. In order to devise these policies it would be essential to explain if there is a relationship between real GDP and unemployment. This relationship, known as Okun's law simply postulates the existence of a negative empirical relationship between changes in the unemployment rate and output. This law is important not only in order to know by how much the output of this country causes changes in unemployment rate but also the mechanism through which these effects take place. The knowledge of this relationship is also important from the point of view of the implementation of appropriate economic policies.

\section{Review of Literature}

At earlier studies Okun estimated 3\% change in Gross Domestic Product due to $1 \%$ change in Unemployment. However advanced econometric techniques and modern data estimated that $1 \%$ change in Unemployment cause more or less than 3 \% change in Gross Domestic Product. Several researchers checked the validity of Okun's law during different time periods by using different econometric techniques for different regions.

Moosa (1997) conducted study for the estimation of Okun's law in four Arab countries(Algeria, Egypt, Morocco, Tunisia). He used the gap model and growth rate model for the estimation. Cyclical components of unemployment and GDP were calculated by applying Hodrick and Prescott Filter (HPF). Time series data from 1990-2005 was obtained from international financial statistics of international monetary fund. Results showed that unemployment and GDP are unrelated in Algeria, Egypt, Morocco and Tunisia. He concluded that Okun's law is valid for these four countries. The existence of Okun's law was also found in Sweden by Arshad in 2007. He examined the association between GDP and unemployment. The gap equation and technique of Hodrick Prescott filter (HP) was used for short run analysis to check Okun's law. Whereas cointegration model and the error correction model is used to test the link between GDP and unemployment in the long and short run. The study showed that the Okun's law exists in the Swedish economy. Javed in 2010 estimated the association between Unemployment rate and GDP growth. To check the validity of Okun's law in Pakistan he used the time series data on Unemployment and GDP during the period of 1981-2005. He used difference version of Okun's law. He employed Engle Granger co-integration method to find the long run relation and Error correction method (ECM) to find the short run behavior of GDP. He found that GDP growth in long run will adjust more quickly towards the equilibrium.

Hussain, et al. (2010) estimated Okun's coefficient. He determined the unemployment and our put relationship with simultaneous equation model. Time serious data for the period of 1973-2005 has been used. He found that one present increase in unemployment is related with 0.33 present decreases in GDP. Okun's ratio is 1:1.20 which is low then the previous estimation but still it is significant. Ahmad at el (2011) conducted study to check the existence of Okun's law in Pakistan economy. They used the difference version and gap version of the Okun's law. They used the time series data on Gross Domestic Product and Unemployment from 1974 to 2009. To find the coefficient of Okun's law they applied the ordinary least square method (OLS).Neither of the models found presence of Okun's law in the economy of Pakistan. To summaries the empirical studies, the several economic and empirical methods are used in different scenarios. In almost every study, there have been used two common variables namely unemployment and output. Gap, difference, dynamic and production-function versions have been used to estimate Okun's coefficient which shows the relationship between unemployment and output. The techniques of the linear time trend, HP filter and the $\mathrm{BP}$ filter have been used to calculate the potential output and natural rate of unemployment. Kalmar has been used to smooth the data in accordance with the error correction model (ECM) and the co integration method for analyzing the link between output and unemployment in short run and long run. This research paper focuses on the estimation of Okun's law in from Pakistan's economy. Earlier studies in Pakistan on the same topic used only one or two versions of this law for the estimation of coefficient. This study includes an additional version (dynamic version) which has not been used before. Coefficient of Okun's law is estimated by difference version, gap version and dynamic version. Extended time period is used in this research paper.

\section{Data and Methodology}

This research paper includes time series data on real GDP and unemployment rate from the economy of Pakistan. The duration of data is from 1972 to 2012. The data on these variables are collected from World development indicator (WDI) and State bank of Pakistan.

In this paper different economic variables have been used. Real GDP and rate of unemployment are main variables. Different versions of Okun's law have been applied. For the application of gap version of this law two variables natural rate of unemployment and potential output are required. Data on these two variables are not available at any source. These variables cannot be measured directly. The variables of Natural rate of unemployment and potential output are constructed through regression analysis.

For the construction of natural rate of unemployment actual rate of unemployment is regressed against trend and predicted values are taken as natural rate of unemployment. Same as real GDP is regressed against trend and predicted values are used as potential output.

\subsection{Theoretical Framework}

\subsubsection{Different Versions of Okun's Law}

Okun's law is based on different versions. All the versions of this law have different specifications and 
properties. All the versions consist of a specific models and these version have different ways to estimate coefficient of this law.

There are following different versions of Okun's law are used in this research.

- The Gap version

- The Difference version

- The Dynamic version

\subsection{The Gap Version}

The Gap version of Okun's law captures unemployment to the gap between actual output and potential output also in the gap version there are some complications involved in order to calculate natural rate of unemployment and potential output which can be calculated using different methods. The gap version can be showed empirically as follows:

$$
\begin{aligned}
& \text { Output gap }=\beta \text { (Unemployment gap) } \\
& \left(Y_{\mathrm{t}}-Y^{*}\right)=\beta\left(\mathrm{U}_{\mathrm{t}}-\mathrm{U}^{*}\right)+C_{\mathrm{t}}
\end{aligned}
$$

Where

$\mathrm{Y}_{\mathrm{t}}=$ Actual out put

$\mathrm{U}_{\mathrm{t}}=$ Actual rate of unemployment

$\mathrm{U}^{*}=$ Natural rate of unemployment

$\mathrm{Y}^{*}=$ Potential output

$\epsilon_{\mathrm{t}}=$ Error term in time period $\mathrm{t}$

$\beta=$ Coefficient of Okun

The argument for the gap version is that it provides a better explanation of unemployment and GDP relationship compared to the dynamic version. The gap version of Okun strives to show the difference between actual and potential output and assume that there will be maximum production level under full employment condition with no pressure of inflation.

\subsection{The Difference Version}

The difference version of Okun's law shows the changes in the unemployment rate from one time period to the next.

The difference version of Okun's law can be empirically expressed as follows:

$$
\left(\mathrm{Y}_{\mathrm{t}}-\mathrm{Y}_{\mathrm{t}-1}\right)=\alpha+\beta\left(\mathrm{U}_{\mathrm{t}}-\mathrm{U}_{\mathrm{t}-1}\right)+C_{\mathrm{t}}
$$

Where

$\mathrm{U}_{\mathrm{t}}=$ Unemployment rate in period $\mathrm{t}$

$\mathrm{Y}_{\mathrm{t}}=$ GDP growth in time period $\mathrm{t}$

$\epsilon_{\mathrm{t}}=$ Error term in time period $\mathrm{t}$

$\mathrm{Y}_{\mathrm{t}-1}=$ Output level at period $\mathrm{t}-1$

$\beta=$ Okun's coefficient

$\alpha=$ Intercept term

In this version GDP growth is regressed changes in unemployment rate, (a rate of change in dependent variable due to independent variable) and its sign can be expected as negative because Okun proposed negative relations between unemployment rate and GDP growth.

\subsection{The Dynamic Version}

The dynamic version shows the past output current of output and past unemployment to affect the unemployment. Arthur Okun also found that in the difference version something is missing as he believed that both current and past level of output effect current rate of unemployment. As far as the drawback is concerned, this version has no simple interpretation as compared to difference version and even gap version. This version has some resemblance with difference version of Okun's law.

$$
\begin{aligned}
& \mathrm{dYt}=\beta_{0}+\beta_{1} \mathrm{U}_{\mathrm{t}}+\beta_{2} \mathrm{U}_{\mathrm{t}-1} \\
& +\beta_{3} \mathrm{U}_{\mathrm{t}-2}+\beta_{4} \mathrm{dY}_{\mathrm{t}-1}+\beta_{5} \mathrm{dY}_{\mathrm{t}-2}
\end{aligned}
$$

(Knotek 2007)

$\mathrm{U}_{\mathrm{t}}=$ Unemployment rate in period $\mathrm{t}$

$\mathrm{Y}_{\mathrm{t}}=$ GDP growth in time period $\mathrm{t}$

$\epsilon_{\mathrm{t}}=$ Error term in time period $\mathrm{t}$

$\mathrm{dY}_{\mathrm{t}-1}=$ Output level at period $\mathrm{t}-1$

$\mathrm{U}_{\mathrm{t}-1}=$ Unemployment at period $\mathrm{t}-1$

$\mathrm{dY}_{\mathrm{t}-2}=$ Output level at period $\mathrm{t}-2$

$\mathrm{U}_{\mathrm{t}-2}=$ Unemployment at period $\mathrm{t}-2$

$\beta=$ Okun's coefficient

$\alpha=$ Intercept term

\subsection{Theoretical Models}

MODEL-1

$$
\left(Y_{\mathrm{t}}-Y^{*}\right)=\beta\left(\mathrm{U}_{\mathrm{t}}-\mathrm{U}^{*}\right)+\epsilon_{\mathrm{t}}
$$

MODEL-2

$$
\left(\mathrm{Y}_{\mathrm{t}}-\mathrm{Y}_{\mathrm{t}-1}\right)=\alpha+\beta\left(\mathrm{U}_{\mathrm{t}}-\mathrm{U}_{\mathrm{t}-1}\right)+C_{\mathrm{t}} .
$$

MODEL-3

$$
\begin{aligned}
& d Y_{t}=\beta_{0}+\beta_{1} U_{t}+\beta 2 U_{t-1}+\beta 3 U_{t-2} \\
& +\beta 4 d Y_{t-1}+\beta 5 d Y_{t-2}
\end{aligned}
$$

\subsection{Estimation of Coefficient through Gap Version}

For the estimation of coefficient through this approach gaps between potential output and real output as well as rate of unemployment and natural rate of unemployment are taken. After that by applying OLS coefficient is determined. decides the intensity of relationship between GDP and rate of unemployment.

$$
\left(\mathrm{Y}_{\mathrm{t}}-\mathrm{Y}^{*}\right)=\alpha+\beta\left(\mathrm{U}_{\mathrm{t}}-\mathrm{U}^{*}\right)+\epsilon_{\mathrm{t}}
$$

\subsection{Estimation of Coefficient through Difference Version}

For the estimation of coefficient through this approach first lags between current and previous real output as well as current and previous rate of unemployment are taken. After that by applying OLS coefficient is determined. decides the intensity of relationship between GDP and rate of unemployment.

$$
\left(\mathrm{Y}_{\mathrm{t}}-\mathrm{Y}_{\mathrm{t}-1}\right)=\alpha+\beta\left(\mathrm{U}_{\mathrm{t}}-\mathrm{U}_{\mathrm{t}-1}\right)+\epsilon_{\mathrm{t}}
$$


After taking one year lag data become stationary so OLS is applied for the estimation of Okun's coefficient.

\subsection{Estimation of Coefficient through Dynamic Version}

For the estimation of coefficient through this approach first and second lags between current and previous real output as well as current and previous rate of unemployment are taken. After that by applying OLS coefficient is determined. decides the intensity of relationship between GDP and rate of unemployment.

$$
\begin{aligned}
& \mathrm{dY} \mathrm{Y}_{\mathrm{t}}=\beta_{0}+\beta_{1} \mathrm{U}_{\mathrm{t}}+\beta_{2} \mathrm{U}_{\mathrm{t}-1}+\beta_{3} \mathrm{U}_{\mathrm{t}-2} \\
& +\beta_{4} \mathrm{dY}_{\mathrm{t}-1}+\beta_{5} \mathrm{dY}_{\mathrm{t}-2}
\end{aligned}
$$

\subsection{Ordinary Least Square Method (Ols)}

To calculate coefficient through all these versions the technique of Ordinary Least Square is used. Regression is a statistical tool for estimating the associations among variables. Regression analysis involves several techniques for analyzing a number of variables and modeling. This method shows relationship between two or more than two variables. Ordinary least squares (OLS) is a technique for calculating the unknown parameters in a linear regression model. This process reduces the sum of squared vertical distances between the observed responses in the dataset and the responses predicted by the linear approximation. The resulting estimator can be expressed by a simple formula, especially in the case of a single regressor on the right hand side. The OLS estimator is consistent when the regressors are exogenous and there is no perfect multicollinearity, and optimal in the class of linear unbiased estimators when the errors are homoscedastic and serially uncorrelated. Under these conditions, the method of OLS provides minimum variance meanunbiased estimation when the errors have finite variances. Under the additional assumption that the errors be normally distributed, OLS is the maximum likelihood estimator. OLS is used in economics, electrical engineering, and political Science among many areas of application.

\section{Results and Discussions}

Empirical results are divided into three sections. Each version is discussed in each section.

\subsection{Section 1}

The Gap version

$$
\left(\mathrm{Yt}-\mathrm{Y}^{*}\right)=\alpha+\beta\left(\mathrm{Ut}-\mathrm{U}^{*}\right)+\epsilon \mathrm{t}
$$

Table 1.1.

\begin{tabular}{|c|c|c|}
\hline \multicolumn{3}{|c|}{ The gap version of Okun's law } \\
\hline Variables & Coefficient & T statistics \\
\hline U & $-6.44 \mathrm{E}-12$ & -4.593137 \\
\hline C & 0.077585 & 0.159313 \\
\hline
\end{tabular}

To check the existence of Okun's law first of all gap version is used. Very small coefficient of Okun's law is found that indicates that there is no existence of Okun's law in Pakistan's economy. But according to Okun's law there exist three to one link between GDP and rate of unemployment and estimated coefficient should be between 2 and 3. So empirical results do not match with theory. Empirical results from gap version did not find the presence of this law because Pakistan is remain economically poor since its dependence. Unemployment never decreased in any period. The standard of our labor force is very low, they are not highly educated and professionals. Increase in RGDP does cause only a minor decrease in unemployment that indicates the non existence of Okun's law. Moosa found the same results. He concluded that there is no existence of Okun's law in Arab countries. Results of this research also supported by the (LAL I) who did not find Okun's law in South Asian countries.

\subsection{Section 2}

The Difference version

Table 1.2.

\begin{tabular}{|c|c|c|}
\hline \multicolumn{3}{|c|}{ The Difference version of Okun's law } \\
\hline Variables & Coefficients & T statistics \\
\hline U & -0.246633 & -2.874767 \\
\hline C & 0.081972 & 1.069670 \\
\hline
\end{tabular}

$$
\left(\mathrm{Y}_{\mathrm{t}}-\mathrm{Y}_{\mathrm{t}-1}\right)=\alpha+\beta\left(\mathrm{U}_{\mathrm{t}}-\mathrm{U}_{\mathrm{t}-1}\right)+C
$$

After getting results from gap version, difference version is used for the estimation of coefficient. The empirical results of this version of Okun's law also show the non existence of this law in Pakistan. Both GDP and rate of unemployment are negatively related with each other that show that with the decrease in unemployment GDP increases and vice versa. But this coefficient is less than required. Estimated coefficient is much low than originally calculated coefficient by Okun. Therefore results indicate that Okun's law does not exist in economy of Pakistan. These results are supported by (Ahmed at el. 2011). They also did not find presence of Okun's law in Pakistan's economy.

\subsection{Section 3}

\subsubsection{The Dynamic Version}

$$
\begin{aligned}
& \mathrm{dY} \mathrm{Y}_{\mathrm{t}}=\beta_{0}+\beta_{1} \mathrm{U}_{\mathrm{t}}+\beta_{2} \mathrm{U}_{\mathrm{t}-1}+\beta_{3} \mathrm{U}_{\mathrm{t}-2} \\
& +\beta_{4} \mathrm{dY}_{\mathrm{t}-1}+\beta_{5} \mathrm{dY} \mathrm{Y}_{\mathrm{t}-2}
\end{aligned}
$$

Table 1.3.

\begin{tabular}{|c|c|c|}
\hline \multicolumn{3}{|c|}{ The Dynamic version of Okun's law } \\
\hline Variables & Coefficients & T statistics \\
\hline $\mathrm{U}$ & -0.184720 & -2.125591 \\
\hline $\mathrm{U}(-1)$ & 0.126956 & 1.021592 \\
\hline $\mathrm{U}(-2)$ & 0.017251 & 0.194678 \\
\hline $\mathrm{DY}(-1)$ & -0.598248 & -3.328647 \\
\hline $\mathrm{DY}(-2)$ & -0.325713 & -1.969752 \\
\hline $\mathrm{C}$ & 0.328443 & 1.407746 \\
\hline
\end{tabular}

\subsubsection{Estimated Model}

$$
\begin{aligned}
& \mathrm{dY}_{\mathrm{t}}=0.328443-0.184720 \mathrm{U}_{\mathrm{t}}+0.126956 \mathrm{U}_{\mathrm{t}-1} \\
& +0.017251 \mathrm{U}_{\mathrm{t}-2}-0.598248 \mathrm{Y}_{\mathrm{t}-1}-0.325713 \mathrm{Y}_{\mathrm{t}-2}
\end{aligned}
$$

Above table shows the estimated results of dynamic version to check the existence of Okun's law in Pakistan. $\beta$ is the coefficient of Okun's law. According to Okun the value of $\beta$ should lie between 2 and 3.But here estimated coefficient is -0.184720 that indicates the same results 
which are estimated by using gap and difference versions. This version also did not find the presence of Okun's law in Pakistan. This version shows the non existence of Okun's law in Pakistan because estimated coefficient is too much low then originally Okun's original coefficient.

\section{Conclusions}

The paper aimed at estimation of Okun's coefficient from the economy of Pakistan to check whether Okun's law is present in Pakistan economy or not. Study focused on annual time series data of Pakistan collected from different reliable sources. Coefficient of Okun's law was estimated by using different versions of this law (gap version, difference version, dynamic version).

The empirical results show that there is no existence of Okun's law in Pakistan's economy. Coefficients estimated by using all the three versions are very small and reject the presence of this law in our economy. So it is concluded that RGDP and unemployment are unrelated in Pakistan. Increase in RGDP cause insignificant decrease in unemployment rate. Okun's law focuses on rapid change in RGDP lowers the $1 \%$ rate of unemployment. But in case of Pakistan it's tough to fine any such type of relationship because of the poor performance of economy since its independence. Pakistan's economy faced a lot of troubles. This country faced wars three times. It was distributed in two parts in 1971. So these initial problems remained our economy non progressive and stagnant.

The main reason of absence of this law is that our labor is not up to date. They are uneducated and unskilled. There found structural and frictional type of unemployment. (Qayyum, 2007). Structural unemployment results from changes in the economy that is not coordinated by changes in training and education. It means that people having no employment not because the economy is in a recession but because people do not have the education and skills to do the available jobs. On the other hand Frictional unemployment results from failure to match job vacancies with the available job seekers. People may have the skills to do certain jobs but they are unaware of the availability of vacant positions that match their skills. It shows the gap between the supply of labor and demand for labor. Producers seeking for specific skilled person for some kind of job but they can't find the person matching to their requirements. At the same time job seekers cannot find jobs according to their wish because of the unavailability of proper guidance and unawareness about different job opportunities around.

\subsection{Recommendations}

This law should exist in all economies, in Pakistan as well. So it is needed to take economy to that level. Policy makers can play vital role in this matter. They should make policies to improve the level of existing labor force and should focus on labor development programs. There should be focus on enhancing the level of labor force. Expenditures on education and training should be increased. More Technical and Vocational training facilities should be provided. In this way unemployed people will get the chance to enhance their skills and become able to earn reasonable income. Seminars and workshops should be arranged to guide the people for the choice of career. Gap between supply of labor and demand for labor should be shorten by giving awareness to people about availability of jobs through media or awareness programs. Further research is needed on the same topic by using remaining versions of Okun's law i.e. production function version. There is need to accelerate economic growth. Sustained growth is the fundamental requirement to reduce unemployment. Macroeconomic stability, investment oriented policies and political stability will be the source to achieve handsome rate of growth. The industrial policy is needed to base on competitive strategy. Export oriented policies is the need of the hour. It is required to establish industrial zones not only surrounding cities but also in remote areas to reduce unemployment. Labor intensive policies must be adopted to reduce unemployment in urban and especially in rural areas. More efforts are needed to improve the Human Capital and developing infrastructure for rapid growth and to minimize unemployment through labor intensive. First of all the policymakers must be creative in creating new jobs, so as to ensure that these jobs match jobseekers talents and skills. Incentives must be given to encourage a balanced blend between the usage of labor intensive techniques of production as well as high tech production capabilities. This will ensure that less skilled labor can still find suitable jobs.

\section{References}

[1] Ahmad, K. Khalil, S. \& Saeed, A. (2010). Does There Exist Okun's Law in Pakistan? International Journal of Humanities and Social Science, 1 (12).

[2] Arshad, Z. (2007). The Validity of Okun's Law in Swedish Economy, Stockholm University.

[3] Hussain, T. M., Siddiqi, W \& Iqbal, A. (2010). A Coherent Relationship between Economic Growth and Unemployment: Empirical Evidence from Pakistan. International Journal of Human and Social Sciences, 5 (5).

[4] Javed, U. (2010). Validity of Okun's Law Empirical Evidence from Pakistan.

[5] Knotek, E. S. (2007). How useful is Okun's law?. Economic Review, 73-103.

[6] Lal, I., Muhammad, S. D., Jalil, M. A. \& Hussain, A. (2010). Test of Okun's Law in Some Asian Countries Co-Integration Approach. European Journal of Scientific Research. 40 (1): 73-80.

[7] Moosa, I. A. (1997). A cross-country comparison of Okun's coefficient. Journal of Comparative Economics, 24, 335-356.

[8] Okun, A. M. (1962). Potential GNP \& Its Measurement and Significance, American Statistical Association, Proceedings of the Business and Economics Statistics Section, 98-104.

[9] Qayyum, W. (2007). Causes of Youth Unemployment in Pakistan. T he Pakistan Development Review, 46 (4): 611-621. 